
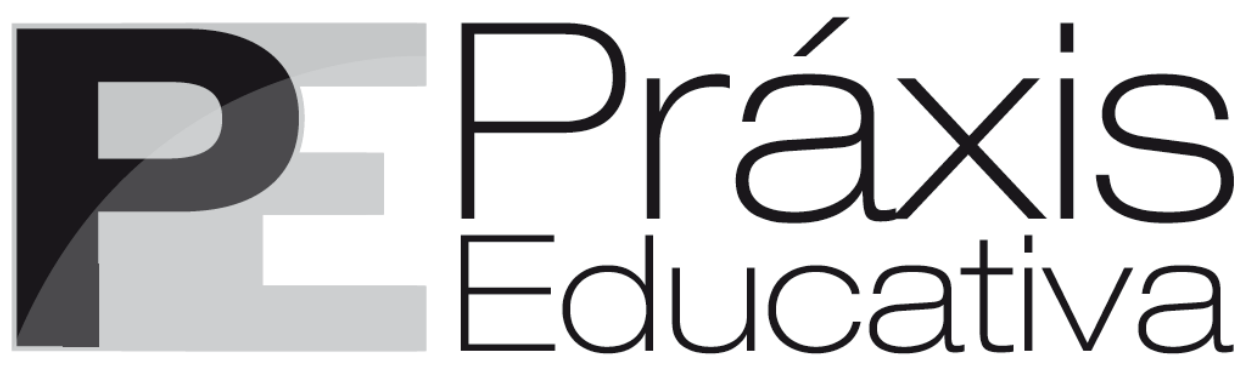

ISSN 1809-4031

eISSN 1809-4309

https://doi.org/10.5212/PraxEduc.v.15.15092.049

\title{
Inclusión de estudiantes migrantes: un desafío para la gestión directiva escolar
}

\section{Inclusão de alunos imigrantes: um desafio para a gestão diretiva escolar}

\section{Inclusion of migrant students: a challenge for school management}

\author{
Jorge Alarcón-Leiva* \\ D https://orcid.org/0000-0001-9915-1949 \\ Catalina Gotelli-Alvial ${ }^{* *}$ \\ https://orcid.org/0000-0001-5994-5007 \\ Myriam Díaz-Yáñez ${ }^{* *}$ \\ https:/ /orcid.org/0000-0002-3067-6306
}

Resumen: En el contexto del progresivo aumento de inmigrantes en Chile, el presente estudio tiene como objetivo caracterizar los principales desafíos que se presentan a la gestión directiva escolar, para integrar a estudiantes inmigrantes extranjeros en escuelas de la Comuna de Talca, Región del Maule Chile. El estudio es de carácter cualitativo y el análisis se lleva a cabo mediante estudio de casos de investigación, utilizando técnicas de análisis de contenido. Para este efecto, se efectuaron entrevistas en profundidad con integrantes de equipos directivos de tres establecimientos educacionales de enseñanza básica, pertenecientes cada uno de ellos a una de las tres dependencias administrativas que caracterizan la provisión mixta del sistema escolar chileno. Los resultados del estudio arrojaron evidencia organizada en las dimensiones de políticas, prácticas y procedimientos utilizados en la gestión directiva escolar de los establecimientos educativos, en relación con procesos de escolarización e inclusión pedagógica de estudiantes inmigrantes extranjeros.

Palabras-clave: Directivos escolares. Gestión educativa. Inmigrantes extranjeros. Escolarización. Inclusión.

\footnotetext{
* Doctor en Filosofía. Académico Facultad de Ciencias de la Educación Universidad de Talca, Chile. Correo electrónico: <joalarcon@utalca.cl>.

** Magister en Política y Gestión Educacional, Universidad de Talca, Chile. Profesora de Educación Básica. Docente de aula. Correo electrónico: <catagot@gmail.com>.

*** Doctora en Ciencias de la Educación con especialidad en Sistemas de Formación. Directora del Centro de Estudios para la Inclusión Intercultural. Universidad Católica del Maule, Talca, Chile. Correo electrónico: <mdiaz@ucm.cl>.
} 
Resumo: No contexto do aumento progressivo de imigrantes no Chile, o presente estudo tem o objetivo de caracterizar os principais desafios que podem se apresentar na gestão escolar, para integrar os estudantes imigrantes estrangeiros nas escolas da Comuna de Talca, Região do Maule, Chile. O estudo é qualitativo e analítico, com estudo de casos de investigação, utilizando técnicas de análises de conteúdo. Para isso, foram realizadas entrevistas em profundidade com equipes diretivas de três escolas, pertencentes às dependências administrativas que caracterizam a provisão mista do sistema escolar chileno. Os resultados do estudo produziram evidências organizadas nas dimensões política, prática e procedimentos utilizados na gestão escolar das escolas, na relação com processos de escolarização e inclusão educativa de alunos imigrantes estrangeiros. Palavras-chave: Diretivos Escolares. Gestão educativa. Migrantes estrangeiros. Escolarizacão. Inclusão.

\begin{abstract}
In the context of the progressive increase of immigrants in Chile, this paper aims at characterizing the main challenges that arise in school management, to integrate foreign immigrant students in schools in the Talca district, Maule Region in Chile. The study is qualitative in nature and the analysis is carried out through research case studies, using content analysis techniques. For this purpose, in-depth interviews were conducted with members of management teams from three educational establishments of Basic Education, each belonging to one of the three administrative units that characterize the mixed provision of the Chilean school system. The results of the study yielded organized evidence in the dimensions of policies, practices and procedures used in the school management of educational establishments, in relation to schooling processes and pedagogical inclusion of foreign immigrant students.
\end{abstract}

Keywords: School directors. Education Management. Foreign immigrants. Schooling. Inclusion.

\title{
Presentación
}

Los movimientos migratorios constituyen una de las características de las sociedades modernas (CASTLES; DE HAAS; MILLER, 2014). De hecho, se estima que el 3,2\% de la población mundial vive fuera de su país de origen lo que equivale a cerca de 214 millones de personas (OIM, 2018). Desde esta perspectiva, la significación de la migración de personas y de grupos se vuelve paulatinamente un fenómeno relevante para explicar las transformaciones culturales de diversos lugares y contextos (CIERANI; GARCÍA; GÓMEZ, 2014; PAVEZ-SOTO, 2017a).

Este último autor observa que, conforme a datos de 2016 en "América Latina y el Caribe existen aproximadamente 7.6 millones de personas migrantes de las cuales $62.8 \%$ representa flujos migratorios entre países de la región" (p. 99). Asimismo, sostiene que "el promedio regional de niñas y niños nacidos en un país distinto al de residencia es de $10.5 \%$ y no existe ninguno cuyo porcentaje supere el 30\%" (PAVEZ-SOTO, 2017a, p. 99). Tal número de población infantil corresponde a niños y niñas que participan en flujos migratorios familiares.

Chile no es la excepción a esta regla general. Desde mediados de la década del 90 y con mayor fuerza a partir del año 2000, el país se ha consolidado como polo de atracción para personas que en su mayoría provienen de naciones de la región latinoamericana, particularmente de Perú, Argentina, Bolivia y, recientemente, Colombia. En efecto, estos son los colectivos más numerosos representando en conjunto cerca del 63\% del total de extranjeros/as en el país (ROJAS; SILVA, 2016). El incremento en la migración sur-sur y, particularmente, con destino a Chile, se debe según (GALAZ; POBLETE; FRÍAS, 2007) al crecimiento económico alcanzado por el país durante la década de los 90 el que promedió tasas del 7\% anual, lo que permitió mayor estabilidad social, económica y también política generando atracción para los habitantes de países vecinos (VARGAS, 2018).

De acuerdo con el último informe del Instituto Nacional de Estadísticas de Chile (INE, 2017) y en concordancia con la información recabada mediante el CENSO respectivo, la cantidad y

Práxis Educativa, Ponta Grossa, v. 15, e2015092, p. 1-24, 2020 Disponível em: <https://www.revistas2.uepg.br/index.php/praxiseducativa $>$ 
porcentaje de inmigrantes internacionales, según período de llegada al país, ha aumentado en un 60,2\% desde antes de la década de los 90 hasta el período de 2010-2017. En el Censo de 2002, 1,27\% de la población residente era inmigrante; 15 años después, el 19 abril de 2017 se censaron 746.465 inmigrantes residentes lo que representa el 4,35\% del total de la población residente en el país (con información declarada en lugar de nacimiento).

Gráfico 1 - Incremento de la población migrante en el país entre 1982 y 2017

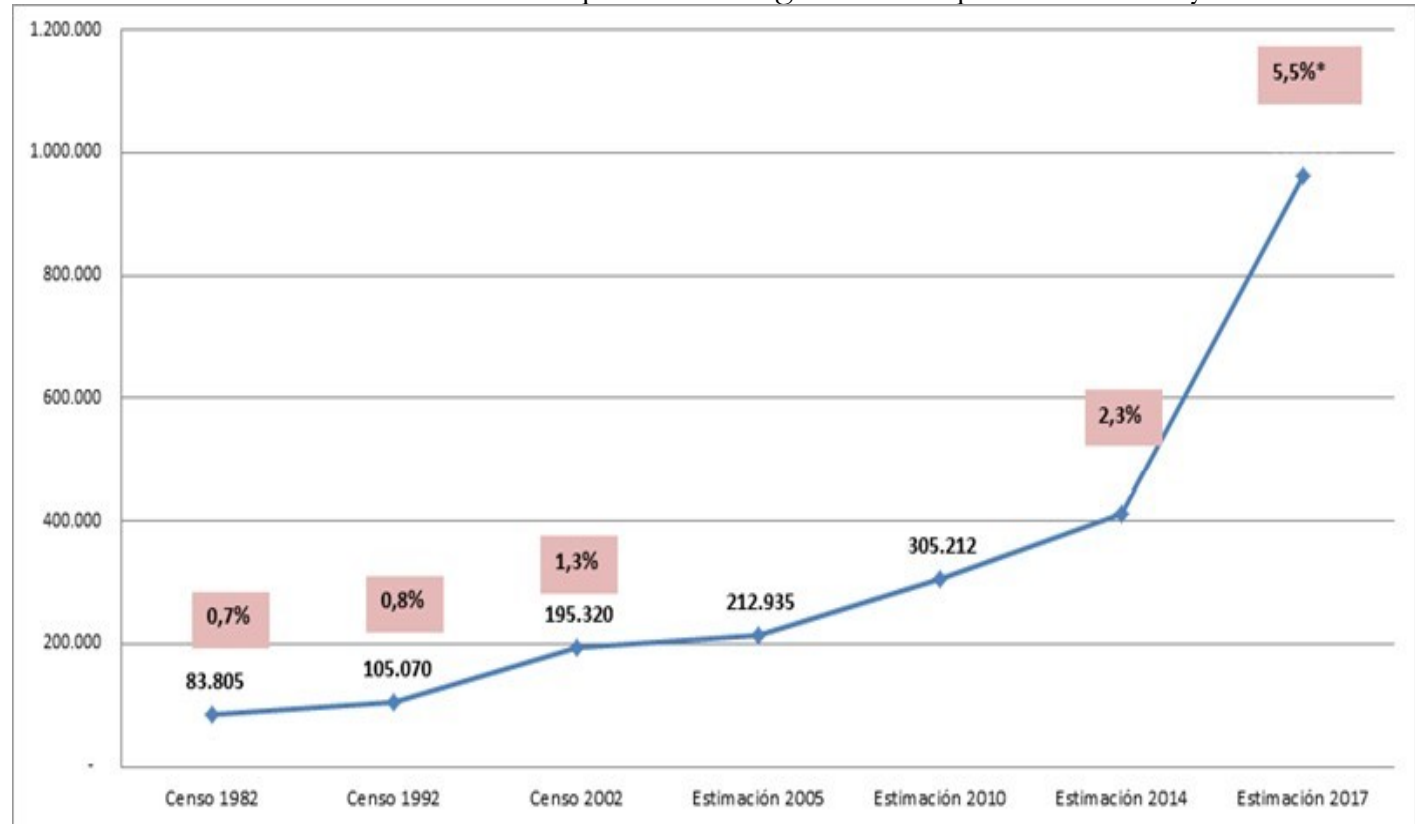

Fuente: Estimaciones DEM en base a Censo 2002 y actualizada con actos administrativos por año.

En cuanto a cantidad bruta de inmigrantes, la Región Metropolitana es el lugar preferido para radicarse. Sin embargo, en cuanto a porcentajes en Santiago los inmigrantes representan un 7\% del total de la población, ubicándose en el cuarto lugar, mientras que en la región de Arica y Parinacota corresponden a un $13,7 \%$ de la población siendo esta la región con mayor porcentaje de inmigrantes con relación a población total.

En los últimos años la migración internacional en la Región del Maule ha alcanzado un aumento significativo aproximándose a cifras cercanas a las 10.780 personas según el Censo 2017. Si bien es cierto, según diferentes fuentes como la encuesta CASEN y el CENSO 2017, señala que la cantidad de años de estudio de la población migrante se encuentra en promedio un punto porcentual por encima de la población nacional. También históricamente ha existido una tensión entre la práctica y las normativas jurídicas existentes, marcada por la ausencia de una política migratoria nacional que se ajuste a las necesidades actuales.

Ante esta situación, no sólo los migrantes enfrentan desafíos en un país con costumbres, cultura e incluso, como ocurre con los inmigrantes haitianos, un idioma diferente, sino que además, el Estado chileno debe exigirse para cumplir con los derechos de personas que ingresan a Chile. Entre esos derechos, la educación es una de las garantías fundamentales a las que debe tener oportunidad toda 
persona y es, por tanto, deber de cada nación proveerla a todos y cada uno de sus habitantes, sean estos nacidos dentro o fuera del país (CONTRERAS; CORTÉS; FABIO, 2010).

En la legislación chilena, el artículo 4to de la Ley General de Educación No 20.370 (CHILE, 2009), establece que el Estado otorgará educación obligatoria en los niveles de enseñanza básica y media, asegurará el acceso y permanencia de los estudiantes, proveerá educación gratuita y de calidad, promoverá la inclusión social, la equidad y velará por la igualdad de oportunidades y la inclusión educativa. Sin embargo, y ante esta declaración, existe evidencia de ciertas dificultades presentadas por el sistema escolar chileno, en cuanto a equidad y calidad.

En efecto, es sabido que de acuerdo con los resultados SIMCE, la escuela chilena presenta una marcada tendencia a reproducir desigualdades sociales. Los/as niños y niñas inmigrantes ingresan a un sistema escolar desigual, con limitaciones para atender a la diversidad. Exactamente en sentido opuesto, un factor que influye directamente en la calidad de la educación es la gestión directiva escolar:

El liderazgo escolar influencia las capacidades, motivaciones y condiciones en que los docentes despliegan sus prácticas pedagógicas en el aula [...] Su importancia radica en la posibilidad de modificar los resultados de aprendizaje de los estudiantes de manera indirecta, a través de una influencia directa en las prácticas docentes. De esta forma, los líderes escolares poseen una responsabilidad última en el éxito o fracaso escolar [...] (ARAVENA et al., 2019).

Una adecuada gestión directiva escolar es directamente proporcional a la calidad. Es decir, a mejor gestión, más calidad. Por lo tanto, uno de los desafíos principales que presentan los equipos directivos de los establecimientos es, precisamente gestionar apropiadamente el desarrollo de los establecimientos escolares. De igual modo, es también necesario determinar qué elementos constituyen los factores determinantes de una buena gestión, a fin de reforzar las prácticas orientadas a ello y mejorar las competencias de los profesionales abocados a la dirección escolar (CAMPOS; VALDÉS; ASCORRA, 2019).

La normativa vigente tiende a ser más bien de orden administrativo y apunta a cómo debe ser el ingreso, permanencia y progreso de la trayectoria educativa de estudiantes inmigrantes extranjeros, poniendo énfasis en que todos deben ser tratados de la misma manera, independiente de su nacionalidad y/o situación migratoria.

Sobre la base en esta evidencia (1), el trabajo se propone situar normativa y teóricamente la gestión educativa en relación con la dirección escolar en Chile (2), con el objeto de caracterizar el contexto de los desafíos de gestión directiva a los que se enfrentan los equipos directivos. Enseguida (3), el texto describe la metodología utilizada para el desarrollo del estudio. A continuación (4) se procede a analizar y discutir los resultados de la realización de la entrevista en profundidad, para finalmente, (5) concluir con algunas recomendaciones a tener en cuenta en relación con cada una de las dimensiones mediante las cuales se agrupan los resultados.

\section{Marco teórico y normativo}

\section{Dirección y liderazgo escolar}

El Marco para la Buena Dirección y el Liderazgo Escolar (en adelante, MBDLE), actualizado el año 2015 (CHILE, 2015a):

Práxis Educativa, Ponta Grossa, v. 15, e2015092, p. 1-24, 2020 
[...] es un documento de política que tiene por objetivo orientar la acción de los directivos de las escuelas y liceos en Chile, así como también su proceso de auto desarrollo y formación especializada. Este instrumento, fija el "norte" hacia el cual debieran orientarse las prácticas directivas para influir de manera efectiva en el mejoramiento de los establecimientos educacionales, por lo que ocupa un lugar protagónico dentro de las acciones del Ministerio de Educación dirigidas a fortalecer el Liderazgo Escolar (CHILE, 2015a, p. 16).

El MBDLE se ha transformado en la base de la dirección de los establecimientos escolares y ha ido tomando fuerza en la medida que se exige competencias a los equipos directivos, que permitan orientar el desarrollo del establecimiento de la manera esperada, esto es, con base en una serie de indicadores de rendimiento que les son exigidos. El MBDLE, además, ofrece una conceptualización de lo que se entiende por liderazgo, gestión y prácticas de liderazgo; presenta, asimismo, cinco dimensiones de prácticas las que, según el mismo instrumento, describen lo que es necesario saber hacer, en términos amplios, para liderar y gestionar una institución escolar de manera efectiva (CHILE, 2015a, p.18ss).

Para Leithwood (2006), el concepto de "liderazgo" se define como "la labor de movilizar e influenciar a otros para articular y lograr los objetivos y metas compartidas" (citado en CHILE, 2015a, p.7). En otras palabras, el liderazgo no es necesario que se identifique con quien desempeña funciones directivas desde una posición administrativa, aunque idealmente así debiera ocurrir. Lo que sí es necesario es que, quien lo ejerza tenga las habilidades requeridas para movilizar los recursos de la comunidad educativa, a fin de lograr las metas propuestas, para estar en sintonía con el Proyecto Educativo Institucional (PEI) del establecimiento (LEIVA-GUERRERO; VÁSQUEZ, 2019).

Es importante que el liderazgo sea positivo, porque de serlo podría, según Leithwood (2006), tener un efecto real en el aprendizaje de los estudiantes. En efecto, un líder positivo capaz de motivar al cuerpo docente, así como a la comunidad en general, generará un equipo con la fuerza necesaria para enfrentarse a los desafíos diarios de la pedagogía, tanto dentro como fuera de la sala de clases (CAMPOS, VALDÉS y ASCORRA, 2019).

En virtud de ello, tal como lo señala el documento del MBDLE (2015, p. 6), se requiere proyectar una política educativa en torno al rol directivo, puesto que se necesita hacer frente a las tendencias y desafíos surgidos como consecuencia de la creciente demanda por el respeto a la diversidad y a las identidades locales. El aprendizaje de los estudiantes, la diversidad y las identidades locales constituyen quizás los ejes prioritarios presentes en el contexto de desenvolvimiento de los sistemas escolares en todo el mundo y, consecuentemente, el liderazgo debe tenerlos como focos prioritarios (RUIZ-TAGLE, 2019).

La diversidad, de hecho, es lo que se ve incrementada por la presencia de inmigrantes en el país, lo cual ha tenido una repercusión significativa en el contexto escolar. Por ejemplo, conforme a datos del Centro de Estudios del Ministerio de Educación de Chile, en 2015 estaban matriculados 30.625 estudiantes inmigrantes extranjeros, cantidad que se duplicó al 2016, alcanzando un total de 61.086 y creció en 2017, ascendiendo a una cifra de 77.608, mientras que en abril de 2018 alcanzaría un 68, 3\% de incremento, con un total de 113.585 estudiantes (CHILE, 2018b, p. 6).

Pero antes que una limitación, el aumento sostenido de estudiantes extranjeros en las escuelas chilenas hace aún más necesario que los directivos y, a su vez los líderes sean quienes promuevan y proyecten activamente una cultura escolar inclusiva, equitativa y de altas expectativas sobre los logros de aprendizaje de los estudiantes y desempeño de todos los miembros del establecimiento. En este 
contexto, la Declaración Universal de los Derechos Humanos (1948, Art. 26), establece que todas las personas sin excepción tienen derecho a la educación. Lo cual está refrendado en la Ley General de Educación de Chile (2009), que establece como principios básicos la universalidad del derecho a la educación, equidad, respeto a la diversidad, integración e inclusión. Asimismo, reconoce el principio de interculturalidad y valora al ser humano en su especificidad cultural y origen, considerando su historia, lengua y cosmovisión.

En esa misma línea, Oliveira (2019) sostiene que la ley brasilera No 13.445/2017 en su artículo $4^{\circ}$ señala que al migrante se le debe garantizar el derecho a la vida, la libertad, igualdad y seguridad y que está prohibida la discriminación por nacionalidad y condición migratoria. Con esta declaración se garantiza la educación para todos los estudiantes migrantes, valorando la diversidad y el derecho a la no discriminación. Sin embargo, en la práctica, y según concluye la autora, el estudiante extranjero se encuentra ausente en la agenda de la educación. Por otra parte, y en un escenario muy similar al anterior, EEUU presenta una brecha respecto del logro educativo de los estudiantes y muestra que las políticas instauradas tienden a incrementar las desigualdades, que afectan directamente a los estudiantes inmigrantes (FRANCO, 2017). Lo anterior, implica un desafío para los líderes y gestores educativos, quienes deben lograr que las normativas y declaraciones prescritas sean implementadas efectivamente en directo beneficio de los estudiantes migrantes.

Por otra parte, en la medida en que la gestión escolar se ocupa de hacer frente a la complejidad característica de los procesos organizacionales, de su sinergia y sostenibilidad, el liderazgo debe contribuir a producir los cambios necesarios para proyectar la organización en un entorno dinámico. La situación era descrita así por Bolívar a mediados de la década de los noventa:

Estamos en un momento de reconceptualización del liderazgo escolar [...] ya sea porque enfoques emergentes nos inducen a extenderlo más allá de las posiciones ocupadas formalmente en la organización [...] ya porque el liderazgo como algo a "ejercer" [...] está en una profunda crisis, en organizaciones convencionales, pero especialmente en organizaciones "educativas". Igualmente se discute si el liderazgo es algo individual, a promover en el grupo, o -mejor- un fenómeno o cualidad de la organización [...]. En fin, el movimiento de reestructuración escolar está dando la vuelta a los planteamientos tradicionales (BOLÍVAR, 1997, p. 25; VÁZQUEZ TOLEDO; BERNAL AGUDO; LIESA ORÚS, 2016).

En este sentido, es una tarea de los equipos directivos guiar, dirigir y gestionar eficazmente los procesos de enseñanza y aprendizaje en los establecimientos educacionales, asegurando la implementación de estrategias para identificar y apoyar tempranamente a los estudiantes que presenten dificultades en los aprendizajes o en los ámbitos conductual, afectivo o social (CHILE, 2015a, p. 25).

Teniendo como referente el MBDLE, se pregunta si los directivos ¿están preparados para identificar y apoyar a los estudiantes que presentan dificultades? Cuando menos puede decirse que deben estarlo, pues el Marco establece que la gestión escolar debe efectuarse, teniendo como guía la transparencia, imparcialidad y la justicia "asegurando el respeto al derecho de la educación por sobre cualquier diferencia (edad, discapacidad, género, raza, etnia, religión, creencias y orientación sexual)". Al mismo tiempo, se debe valorar, promover y "hace respetar la diversidad social y cultural de su comunidad" (CHILE, 2015a, p. 31).

La pregunta que se ha planteado tiene sentido puesto que el MBDLE ofrece lineamientos que, a grandes rasgos, orientan a los equipos directivos en su quehacer cotidiano, pero pudiera ocurrir que los equipos directivos estén cumpliendo con el MBDLE, sin necesidad de llevar a cabo prácticas que incluyan de manera efectiva a los estudiantes inmigrantes extranjeros. La sola exigencia por inclusión

Práxis Educativa, Ponta Grossa, v. 15, e2015092, p. 1-24, 2020 Disponível em: <https://www.revistas2.uepg.br/index.php/praxiseducativa $>$ 
Jorge Alarcón-Leiva, Catalina Gotelli-Alvial e Myriam Díaz-Yáñez

no parece dar suficiente cuenta de la especificidad de la situación de los estudiantes inmigrantes extranjeros.

El MBDLE fue actualizado el año 2015, por lo que no deja de ser curioso que a pesar de que los datos estadísticos muestran un aumento significativo del número de extranjeros en el país entre 2010 y 2015 y, en consecuencia, un aumento en la matrícula de niños y niñas inmigrantes en las escuelas chilenas, particularmente en las públicas, no se haya explicitado lo que se debe hacer desde la perspectiva de su escolarización e inclusión pedagógica.

\section{Gestión de la diversidad, escolarización e inclusión educativa}

El hecho que el ajuste entre el MBDLE y los cambios que se han producido en términos del incremento de la inmigración no se haya previsto, motiva dos consideraciones preliminares de distinto tenor sobre las normativas.

La primera, concierne al valor de la escuela como agente de socialización (PAVEZ-SOTO, 2017; SUÁREZ-CABRERA, 2015). Es en ella donde se puede generar -si acaso- cambios sustanciales en la forma y fondo de una comunidad. Los equipos directivos se enfrentan en las escuelas al desafío que supone escolarizar e incluir estudiantes de diferentes culturas en una institución que se ha caracterizado, para bien y para mal, por tender a la homogeneidad. Para dar respuesta a estos desafíos es necesario que se generen, a nivel de las escuelas, propuestas inclusivas que reconozcan y den respuesta a la diversidad de sus estudiantes con independencia de su origen nacional y cultural (CHILE, 2016a).

La segunda consideración, deriva de contrastar este desafío directivo con la clase de orientaciones sobre la inclusión educativa de estudiantes (CHILE, 2017b). En el documento sobre orientaciones técnicas para la inclusión educativa de estudiantes extranjeros (CHILE, 2017b) se ofrecen orientaciones de acuerdo con los ejes estratégicos para el diseño e implementación de acciones basadas en el marco del Plan de Apoyo a la Inclusión (CHILE, 2016a), en los ámbitos de instrumentos normativos y de gestión institucional, conocimiento de los estudiantes y sus trayectorias, así como gestión y prácticas en el establecimiento.

De igual manera en 2018 se formula la Política Nacional para Estudiantes Extranjeros (CHILE, 2018b) que modifica, entre otras cosas, el IPE que si bien permitía el ingreso de los estudiantes migrantes al sistema escolar chileno los dejaba fuera de una serie de beneficios a los que sí pueden acceder los estudiantes nacionales como, por ejemplo: apoyo escolar, útiles y becas de alimentación, computador portátil en $7^{\circ}$ básico (Programa "Me Conecto para Aprender"); Programas de apoyo pedagógico, tales como PACE, PIE y SEP; reconocimiento de trayectoria escolar (SIGE) y certificación de estudios por parte de Ministerio de Educación. Ranking de notas y/o NEM para el ingreso a la educación superior, inscripción para rendir la Prueba de Selección Universitaria (PSU) (CHILE, 2018b, p.10). En gran medida se trata de orientaciones y normas preferentemente de orden administrativo, i. e., se refieren a los mecanismos para institucionalizar a los estudiantes.

El desafío es en cambio un proceso más complejo en cuanto busca la real participación de los estudiantes (y, por consecuencia, de sus familias) en la comunidad con el fin de conseguir su inclusión social. Para realizar una verdadera inclusión de estudiantes inmigrantes extranjeros se hace necesario, primero, el reconocimiento y valoración de su cultura como un aporte al desarrollo del país. Para luego,

Práxis Educativa, Ponta Grossa, v. 15, e2015092, p. 1-24, 2020 Disponível em: <https://www.revistas2.uepg.br/index.php/praxiseducativa $>$ 
realizar una conjugación entre ambas culturas y generar una nueva, donde ambas partes sean igualmente importantes y significativas. En esta línea, y según Poblete, el cambio escolar para la inclusión supone un conjunto de reformas de distinta envergadura y orientación, sin embargo, al hacer referencia a las escuelas con presencia de grupo de niños y niñas migrantes, se suelen señalar tres elementos: actitudes de directivos y docentes, transformaciones al currículum y estructura escolar (POBLETE et al., 2007).

Por su parte, JORDÁN (1994) afirma que los docentes y directivos muestran dos opiniones distintas. La primera, en el plano consciente, dice que están abiertos a la inclusión de niños inmigrantes, mientras que, en el plano inconsciente sus actitudes son mucho más negativas. Esto puede ocurrir dado que es muy difícil conseguir que el profesorado que lleva años siendo parte de un sistema escolar homogeneizador, logre cambiar el paradigma con el cual opera. En la medida que exista desconocimiento sobre los procesos, prácticas y políticas que orienten el camino hacia la escuela intercultural, la realidad seguirá siendo manejada por el plano inconsciente de los docentes y directivos de las escuelas, generando una relación asimétrica donde los/as estudiantes inmigrantes extranjeros/as están —en un sentido relevante- por debajo de los nacionales.

En este sentido, la propuesta de JIMÉNEZ (2014a) subraya la necesidad de avanzar en comprender "la dificultad o incluso la imposibilidad de lograr el éxito escolar del alumnado minoritario si la escuela como institución se muestra insensible a los cambios sociales y continúa operando -desde el punto de vista de su estructura, funcionamiento y oferta curricular- bajo una lógica monocultural, no promoviendo, por tanto, el despliegue de continuidades entre la cultura escolar y las culturas minoritarias" (JIMÉNEZ, 2014a, p. 411). El éxito en cuestión no alude solo a los resultados académicos, sino a aquello más fundamental perseguido por las instituciones escolares de una nación, lo que se expresa en cohesión social. Tampoco, se advierte, depende de una variable puramente individual, sino que afecta al conjunto de la escuela (JIMÉNEZ, 2014a).

En función de subrayar esta diferencia el artículo usa diferenciadamente y de forma sistemática los conceptos de "escolarización y de "inclusión”. De igual modo ocurre con sus respectivos correlatos, esto es, "desescolarización" y "exclusión". Por "escolarización” unificando una serie de aproximaciones a la noción, se entiende como los procesos de ingreso y matrícula de los/as estudiantes inmigrantes extranjeros en un establecimiento educativo Es decir, por "escolarización" se ha de entender "acceso" (JIMÉNEZ et al., 2017a, p. 106).

Por contraste, se utilizará "inclusión" para referir a procesos de "participación y aprendizaje" de los/as estudiantes inmigrantes extranjeros/as una vez que ya ha ingresado en un establecimiento educativo.

En este último sentido, JIMÉNEZ et al. (2017a) examinan documentos en el sistema educativo nacional desde la perspectiva de los sistemas de acogida de estudiantes inmigrantes extranjeros, pudiendo establecer una diferencia entre dos funciones de los documentos, a saber, una función "informativa" y otra función "instructiva".

Esta distinción se ajusta a la evaluación que se ofrece de la relación que mantienen los directivos escolares con los documentos de política emanados desde los organismos gubernamentales en Chile. Asimismo, la noción de "inclusión" referida a "participación y aprendizaje" permite establecer el tipo de enfoque en el marco del cual se desarrolla la forma de integración de los/as estudiantes inmigrantes 
Jorge Alarcón-Leiva, Catalina Gotelli-Alvial e Myriam Díaz-Yáñez

extranjeros/as en el establecimiento escolar que, en nuestro caso, distingue entre "monocultural", "multicultural" e "intercultural".

En el primer enfoque se define a la escuela, cuya gestión se asemeja a lo que tradicionalmente se ha conocido, como "asimilación" y "separación" que tienen lugar en las circunstancias en que el inmigrante adopta una relación de subordinación frente a la cultura mayoritaria o dominante. En el segundo caso, la multiculturalidad se entiende como un fenómeno de "integración" de las tradiciones culturales del inmigrante con la comunidad cultural de destino. Finalmente, la relación será intercultural cuando el inmigrante se mantiene "marginado" de la comunidad de destino, con la finalidad de sostener los rasgos de la cultura de origen por sobre la cultura de destino (BERRY et al., 2006).

\section{Metodología}

El presente estudio se inscribe en el paradigma cualitativo, de carácter descriptivo, puesto que su objetivo es caracterizar los desafíos que se presentan a los equipos directivos de tres escuelas de la comuna de Talca para una adecuada escolarización e inclusión de estudiantes inmigrantes extranjeros en sus respectivos establecimientos.

Como técnica de recolección de datos se utilizó una entrevista semiestructurada, realizada con equipos directivos de tres establecimientos educativos de la comuna de Talca, que corresponden a cada una de las dependencias del sistema: municipal (de propiedad pública y fondos públicos $=\mathrm{X}$ ), particular-subvencionada (de propiedad privada, pero que recibe fondos públicos $=\mathrm{Y}$ ) y privada (de propiedad privada y recursos privados $=\mathrm{Z}$ ). En consecuencia, en lo sucesivo X, Y, Z constituirá en cada caso una síntesis de las opiniones de los equipos directivos de los establecimientos educativos estudiados.

Según DÍAZ-BRAVO et al. (2013, p. 163), este tipo de entrevistas “presentan un grado mayor de flexibilidad que las estructuradas debido a que parten de preguntas planeadas que pueden ajustarse a los entrevistados. Su ventaja es la posibilidad de adaptarse a los sujetos con enormes posibilidades para motivar al interlocutor, aclarar términos, identificar ambigüedades y reducir formalismos". La realización de las entrevistas semiestructuradas contempla las siguientes fases:

Tabla $\mathbf{N}^{\circ} 1$ - Fases de entrevistas semiestructuradas

\begin{tabular}{|c|c|c|}
\hline \multirow{3}{*}{$1^{\text {a }}$ Fase } & \multirow[b]{3}{*}{ Preparación } & Reunir y revisar antecedentes previos \\
\hline & & Planificar la entrevista \\
\hline & & Preparar la cita \\
\hline \multirow{2}{*}{ 2a Fase } & \multirow[b]{2}{*}{ Apertura } & Declarar motivo, confidencialidad y duración \\
\hline & & Convenir propósitos y condiciones de realización \\
\hline \multirow[b]{2}{*}{$3^{\text {a }}$ Fase } & \multirow[b]{2}{*}{ Desarrollo } & Intercambiar información \\
\hline & & Identificar puntos de acuerdo \\
\hline \multirow{2}{*}{$4^{a}$ Fase } & \multirow[b]{2}{*}{ Cierre } & Elaborar las conclusiones \\
\hline & & Realizar síntesis \\
\hline
\end{tabular}

Fuente: Adaptación de Díaz-Bravo et al. (2013, p. 164).

Práxis Educativa, Ponta Grossa, v. 15, e2015092, p. 1-24, 2020

Disponível em: <https://www.revistas2.uepg.br/index.php/praxiseducativa $>$ 
El análisis de las entrevistas se realizó mediante el Programa Nvivo ${ }^{\circledR}$ 12, con el propósito de "recopilar y analizar datos [que] conduce al surgimiento de nuevas categorías (emergentes) durante el proceso de interpretación y teorización que conduce a valiosos resultados" (DÍAZ-BRAVO, 2013a, p. 165). En el proceso de análisis "los contenidos de las entrevistas [se analizan] a través de la triangulación (integración de elementos teóricos, documentos y testimonios)", con el objeto de ofrecer una imagen robusta de la evidencia (DÍAZ-BRAVO, 2013a, p. 165).

En el proceso de interpretación, se realizó mediante la categorización, análisis y triangulación de la información obtenida, y se ofrecerá una en el apartado siguiente una presentación de la misma, organizada conforme a las dimensiones del Marco para la Buena Dirección y Liderazgo Escolar (CHILE, 2015a), cuya comprensión se expone enseguida.

\section{Dimensión Genérica}

Para contextualizar los establecimientos educacionales de los entrevistados, se realizan preguntas generales que permitirán conocer las características de la escuela seleccionada. Esta dimensión aporta información sobre la cantidad de estudiantes inmigrantes extranjeros y su nacionalidad, el aumento o disminución de niños y niñas extranjeros en la matrícula y su respectivo porcentaje respecto del total, la percepción que tienen los equipos directivos sobre las diferencias que se presentan entre ellos y el año desde el que están recibiendo estudiantes extranjeros.

\section{Dimensión de Políticas}

Esta dimensión busca ahondar en lo que conocen los equipos directivos de las escuelas seleccionadas sobre las políticas públicas relacionadas con estudiantes migrantes y la opinión que estas le merecen. Por otra parte, busca conocer si los establecimientos cuentan con políticas internas que permitan la inclusión de estudiantes inmigrantes extranjeros o si existe un reglamento interno que asegure una evaluación inclusiva atendiendo a sus diferencias. Para terminar los directivos darán su opinión sobre la afirmación "Estudiantes inmigrantes extranjeros tratados diferenciadamente tienen mayor éxito escolar que aquellos que se integran sin diferencias con el resto de sus pares".

\section{Dimensión de Procedimientos}

Esta dimensión, indaga sobre los procedimientos existentes y utilizados en la escuela para la escolarización e inclusión de estudiantes extranjeros. Para esto, los directivos respondieron si creen que el establecimiento ha fomentado la inclusión de estudiantes migrantes a nivel curricular o, si es que existen procedimientos internos relacionados con la adecuación de la evaluación de estudiantes migrantes. En otra arista de esta misma dimensión, se obtendrá información de la tasa de aprobación o reprobación y la impresión que les merece el desempeño académico del estudiantado inmigrante extranjero.

\section{Dimensión de Prácticas}

Esta dimensión busca clarificar si los establecimientos educacionales realizan prácticas que permitan el ingreso, permanencia y el debido cumplimiento de los derechos de estudiantes inmigrantes 
Jorge Alarcón-Leiva, Catalina Gotelli-Alvial e Myriam Díaz-Yáñez

extranjeros en los establecimientos. En un segundo momento, esta dimensión ahonda en las prácticas que llevan a cabo para la inclusión de este grupo de estudiantes y la vinculación con sus familias. Para terminar, los entrevistados manifestarán qué tareas están pendientes en cuanto a políticas públicas educativas para estudiantes inmigrantes extranjeros, desde la perspectiva de su experiencia como directivo.

\section{Resultados y discusión}

Los resultados de la realización de la entrevista se examinan a continuación y se presentan a continuación, agrupando las respuestas consideradas relevantes en cada una de las dimensiones descritas en la metodología y discutiendo el alcance de la evidencia que el trabajo en terreno puso a disposición del estudio.

\section{Dimensión Genérica}

Esta dimensión aporta información sobre la cantidad de estudiantes inmigrantes extranjeros y su nacionalidad, el aumento o disminución de niños y niñas extranjeros en la matrícula y su respectivo porcentaje respecto del total, la percepción que tienen los equipos directivos sobre las diferencias que se presentan entre ellos y el año desde el que están recibiendo estudiantes extranjeros.

Como se indicó, para contextualizar la situación de los establecimientos educacionales, se planteó algunas preguntas sobre las características de las instituciones en relación con la inmigración. En este sentido, los establecimientos X e Y, informan haber experimentado un incremento de $30 \% \mathrm{y}$ un incremento, que se viene percibiendo desde el año 2016, de entre $70 \%$ y $80 \%$, respectivamente en el número de estudiantes inmigrantes extranjeros que se matriculan. En opinión de los directivos, el solo "aumento en el número de estudiantes inmigrantes, ha hecho evidente la necesidad de hacerse cargo de la nueva situación creada por este hecho" (CHILE, 2018a).

En el establecimiento $\mathrm{Y}$, el director hace referencia a que sí existen diferencias entre los estudiantes, pero "más que nada en cuanto a frases típicas de cada país", no a "diferencias sustanciales" entre ellos (los/as estudiantes inmigrantes extranjeros/as). En el mismo sentido, se pronuncian los directivos de los demás establecimientos entrevistados.

Cuando el director del establecimiento dice que no existen diferencias sustanciales entre niños y niñas nacionales y extranjeros, pasa por alto la importancia que tiene el lenguaje en la expresión de las particulares visiones de mundo de las personas (POZZO; SOLOVIEV, 2011a). En efecto, la elaboración lingüística es el resultado del contacto que le corresponde vivir a cada pueblo "en distintos territorios geográficos, contextos y periodos históricos", los que difieren de otros pueblos. Es posible, inclusive, que esta diferenciación tenga lugar entre colectivos y también puede verse "que se produce dentro del mismo colectivo lingüístico” (POZZO; SOLOVIEV, 2011a, p.199).

Por ejemplo, un estudiante chileno dirá "amigo", para referirse a alguien por quien siente confianza o simpatía, mientras que un/a estudiante venezolano/a utilizará la palabra "chamo" y un colombiano utilizará la expresión "pana". Sin entrar siquiera en detalles, resulta manifiesto que no se trata solo de usar palabras distintas para la misma referencia, puesto que cada una de esas palabras designa, de hecho, a una clase de vínculo interpersonal, cuyo contenido específico no es el mismo en los tres casos.

Práxis Educativa, Ponta Grossa, v. 15, e2015092, p. 1-24, 2020 
El "desplazamiento" que se produce en el significado de las tres expresiones, en virtud de lo cual puede decirse que se refiere a vínculos interpersonales idiosincrásicos, deriva del contexto de su uso, así como de la historia y las implicaciones tanto subjetivas como intersubjetivas de los hablantes. El contexto, la historia y la psicología de los usuarios de las palabras producen consecuencias semánticas relevantes en esas mismas palabras, pues en todos los casos devienen como resultado de trayectorias vitales, individuales y colectivas, que constituyen distintas "realidades" localizadas temporal y espacialmente de formas precisas (POZZO; SOLOVIEV, 2011a).

\section{Dimensión de Políticas}

Sobre la base en las respuestas de los entrevistados, se desprende que el conocimiento que tienen de las políticas proviene únicamente de la información entregada por el Ministerio de Educación. En lo fundamental, los entrevistados reportan una forma de relación con las normativas que JIMÉNEZ et al. (2017a) llaman “informativa e instructiva”. Se trata de documentos:

[...] emitidos por los diferentes gabinetes destinados a organismos gubernamentales con el propósito de entregar información y/o prescribir la implementación de determinadas acciones/decisiones [...] los oficios buscan poner en conocimiento a otros ministerios y comunidades educativas respecto a decisiones tomadas en materia de escolarización de estudiantes inmigrantes (JIMÉNEZ et al., 2017a, p. 108).

En consecuencia, existe una relación entre escolarización, esto es, acceso y matriculación de estudiantes inmigrantes extranjeros en este caso, y uso informativo e instructivo, prescriptivo, cabría decir, de las normas elaboradas por el Ministerio de Educación. Debido a ello, es llamativo que los entrevistados señalen que al usar de esta forma los documentos ministeriales estén "incluyendo" a los estudiantes, cuando lo que hacen es no más que brindarles la oportunidad de acceder, lo que se corresponde con el derecho de niños y niñas.

De hecho, al reportar la forma de proceder a este respecto, los entrevistados señalan que los establecimientos - sin distinción- tratan a todos/as los/as estudiantes "por igual". Sin embargo, en verdad, se puede inferir que cuando hablan de inclusión se refieren a una forma de asimilación, es decir, los estudiantes extranjeros que son recibidos en sus escuelas y asimilados al modelo de trato pedagógicamente "igualitarista" - si por ello se entiende: "suprimiendo toda diferencia" - (ECHEITA; SANDOVAL, 2002).

No existe internamente ninguna política establecida para la integración de los/as estudiantes inmigrantes extranjeros/as. Es decir, los establecimientos entienden como obligatoria la escolarización de estos estudiantes a causa de su observancia de las políticas educativas, pero no gestionan internamente ni procedimientos ni prácticas que favorezcan su inclusión en el sentido de "participación y aprendizaje".

La actitud que se manifiesta a través de la respuesta del director del establecimiento "Y" es de temor por las posibles consecuencias que podría tener el querer "hacer de más" para la inclusión de los estudiantes extranjeros. Al decir esto, el director deja en evidencia que espera que la ley sea explícita al señalar lo que se debe hacer con estudiantes inmigrantes extranjeros y, en consecuencia, el establecimiento escolar no definirá ningún procedimiento ni práctica propia de manera formal, a menos que la ley lo mande. 
Jorge Alarcón-Leiva, Catalina Gotelli-Alvial e Myriam Díaz-Yáñez

Que los establecimientos no cuenten con políticas internas inclusivas de participación y aprendizaje repercute directamente en la evaluación que se aplica a estudiantes inmigrantes extranjeros. Esto significa que tanto estudiantes chilenos/as como extranjeros/as son evaluados/as de la misma manera y solo se hacen excepciones en el caso que el alumno "no hable español". Estas excepciones, sin embargo, se realizan de manera voluntaria y discrecional por parte de los/as profesores/as por lo que se infiere que de no haber dicha voluntad la evaluación se aplica a todos por igual.

La situación concerniente a la evaluación, es decir, la idea del predominio de una suerte de principio de "igualdad de práctica para todos", corre el riesgo de contravenir las normas a este respecto que establecen que cuando se recibe estudiantes de un país que no está dentro del convenio de convalidación de estudios y, además, habla otro idioma, el establecimiento debe esperar al tercer trimestre del año para realizar una evaluación de los contenidos mínimos que debería presentar el estudiante para ubicarlo en un nivel determinado del currículum.

Una vez más podemos ver que, de acuerdo con la información obtenida, los tres establecimientos entrevistados tienen un trato homogeneizador con el alumnado extranjero lo que apunta a que el tipo de escuela, según la gestión escolar aplicada, es asimilacionista, porque el currículo está preparado para el estudiantado promedio, de determinada clase social, con determinados ingresos familiares y con un determinado tipo de vivienda (JIMÉNEZ GÁMEZ, 2004) lo que deja poco espacio para la inclusión de los estudiantes inmigrantes extranjeros.

Dado que los directivos consultados se desempeñan en establecimientos en que aumentó de manera explosiva la matrícula de estudiantes inmigrantes extranjeros durante el 2018, los establecimientos que reciben subvención del Estado han pensado modificar sus reglamentos internos y así satisfacer los requerimientos que surgen al tener población inmigrante en la escuela. Por otra parte, la entrevistada del establecimiento Z (privado con financiamiento privado), sostiene que no han pensado modificar el Proyecto Educativo Institucional (PEI) porque "nuestro colegio es inclusivo por lo que no discriminamos a nadie, por lo tanto, los estudiantes de otras nacionalidades son bienvenidos como un chileno más".

A modo síntesis, y relacionando lo analizado en esta dimensión con la opinión que tienen los directivos sobre la siguiente afirmación "Estudiantes inmigrantes extranjeros tratados diferenciadamente tienen mayor éxito escolar que aquellos que se integran sin diferencias con el resto de sus pares", se puede concluir que, a pesar de que los entrevistados manifiestan estar de acuerdo con esta afirmación, la realidad en sus establecimientos dice lo contrario. Los directivos entrevistados conocen poco sobre la normativa vigente, ninguno de los tres mencionó, por ejemplo, la actual política nacional de estudiantes extranjeros 2018-2022. Al desconocerla se genera en ellos un sentimiento de temor porque sienten que la ley no los respalda para realizar modificaciones en los reglamentos internos.

\section{Dimensión de Procedimientos}

Cuando se les pregunta a los entrevistados si es que ellos creen que su establecimiento favorece la inclusión a nivel curricular, dos comentan que sí. Ambos aseguran que tienen algunos profesores que realizan actividades para incluir a los estudiantes inmigrantes extranjeros. 
La Jefa de Unidad Técnico Pedagógica del establecimiento Z, menciona que en las clases de inglés se realizan actividades donde los niños extranjeros pueden mostrar sus costumbres al resto del grupo curso. Técnicamente hablando y por lo reportado por los entrevistados, lo que hace en el establecimiento $Z$ no corresponde a modificaciones curriculares en sentido estricto porque, el llevar a cabo estas iniciativas no queda claro el sentido, si lo que se promueve a través de ellas es la preservación de la cultura de los estudiantes inmigrantes o, más bien, se trata de una exposición de sus costumbres como una forma de participar.

En este sentido, el director del establecimiento Y, reporta que el profesor de educación física ha realizado modificaciones al currículo y ha incluido los bailes típicos de los países de los estudiantes extranjeros. De acuerdo con el enfoque para la reforma multicultural del currículo de BANKS (1989), lo que ha realizado el profesor de educación física corresponde al "enfoque de contribuciones" (nivel 1 de los 4 niveles de integración de contenido étnico al currículo), ya que presentar bailes típicos es una manera rápida de hacer que los estudiantes inmigrantes extranjeros se sientan parte de la escuela y que sus compañeros conozcan algo de su cultura. En este mismo establecimiento, "en las clases de historia, un profesor que ha estudiado los procesos históricos de países vecinos a Chile y ha hecho paralelos, compara en clases lo que pasaba en Chile y en los países de los estudiantes inmigrantes". Esta modificación correspondería al "enfoque de transformación" (correspondiente al tercer de los 4 niveles propuestos por BANKS, 1989), porque el docente ha transformado el currículo, haciendo ver a los alumnos la misma época desde diferentes puntos de vista.

En cuanto a la gestión pedagógica de estas iniciativas, cabe preguntarse ¿de qué manera el equipo directivo se cerciora de que las modificaciones realizadas por los profesores estén adecuadamente ejecutadas? No basta con la voluntad de hacer cosas, esa es una primera parte, pero no es la única. El equipo directivo específicamente el área de Unidad Técnico Pedagógica debe velar porque los cambios realizados al currículo sean pertinentes a las necesidades de los estudiantes y no queden sujetas a la buena voluntad o proactividad de cada docente.

Por otra parte, la Jefa de Unidad Técnico Pedagógica de la escuela X, comenta que en su escuela no se realizan modificaciones a nivel curricular, dado que la ausencia de normativa a nivel país no los respalda como equipo directivo al momento de pedir al profesorado hacer adecuaciones curriculares. Una vez más, en palabras de la entrevistada del establecimiento $\mathrm{X}$ y del director del establecimiento $\mathrm{Y}$, aparece el sentimiento de temor por pedir de manera formal a los docentes que realicen procedimientos inclusivos para y por los estudiantes extranjeros.

Para evaluar a los estudiantes inmigrantes extranjero se aplica el mismo reglamento de evaluación que a todos los estudiantes. Los establecimientos que cuentan con Proyecto de Integración Escolar (PIE) consideran modificaciones curriculares y evaluativas, pero solo para niños y niñas que presentan algún trastorno de aprendizaje, sea este transitorio o permanente. Los estudiantes inmigrantes extranjeros no califican dentro de este grupo, por lo que deben ser evaluados como todos. Sin embargo, a pesar de no haber ningún reglamento de evaluación formal y ningún procedimiento evaluativo sistematizado dos de los tres directivos de establecimientos declaran que sí han hecho, en alguna oportunidad, ajustes en las evaluaciones de los alumnos extranjeros, relacionados principalmente con el idioma de los instrumentos evaluativos.

La UTP de la escuela Z, argumenta que no pueden realizar modificaciones a los reglamentos internos de la escuela por la ausencia de lineamientos claros por parte del Ministerio de Educación, mientras que la realidad es que este, a través de distintos documentos relacionados con la gestión de

Práxis Educativa, Ponta Grossa, v. 15, e2015092, p. 1-24, 2020 Disponível em: <https://www.revistas2.uepg.br/index.php/praxiseducativa $>$ 
Jorge Alarcón-Leiva, Catalina Gotelli-Alvial e Myriam Díaz-Yáñez

los establecimientos, apunta cada vez más a la autonomía de los equipos de gestión en la toma de decisiones (CHILE, 2018b).

Los indicadores de eficiencia interna, permiten que los equipos directivos y profesores estén permanentemente monitoreando el funcionamiento del curso y establecimiento. Por esto se consulta a los entrevistados si es que manejan, en datos numéricos, la tasa de aprobación o reprobación de los estudiantes inmigrantes extranjeros. Los directivos de los tres establecimientos responden que no disponen de la información, porque el Sistema de Información General del Estudiante (SIGE) no entrega información diferenciada entre estudiantes chilenos y extranjeros, sólo los divide por género y curso y ellos, como establecimiento, tampoco han hecho esta subdivisión.

A pesar de no disponer de los datos cuantitativos sobre el rendimiento académico de los estudiantes inmigrantes extranjeros, los directivos tienen su propia apreciación sobre esto. Por una parte, la Unidad Técnico Pedagógica del establecimiento Z, menciona que "son buenos estudiantes", puesto que se trata de hijos de padres profesionales con un bagaje cultural que aporta mucho al aprendizaje de los niños. Mientras que la Unidad Técnico Pedagógica del establecimiento Z, señala que hay niños en distintos niveles: "unos muy buenos, que vienen muy bien formados desde la casa y otros que están en cuarto básico y no manejan la lectura por lo que han tenido que nivelarlos con sus compañeros". Un panorama similar ocurre en el establecimiento $\mathrm{Y}$, donde el director dice que "el rendimiento de los estudiantes inmigrantes es relativamente bueno, pero que la condición socioeconómica de algunos de ellos es un antagonista importante para un adecuado aprendizaje".

\section{Dimensión de Prácticas}

Los directivos consultados manifiestan que no existen prácticas que aseguren el ingreso de los niños extranjeros. Lo que dicen hacer los establecimientos es permitir que, en el caso de haber matrícula, cualquier postulante sea este inmigrante o no pueda ser matriculado. En cuanto a la permanencia los establecimientos hacen lo que harían con cualquier estudiante nuevo, los reciben y luego dejan que se desenvuelven de acuerdo con sus características personales.

Las respuestas dejan en claro que las prácticas que realizan no son diferenciadas y que lo que ellos llaman "para todos lo mismo, para todos igual" es una idea que no permite la inclusión, dado que cuando nos referimos a este concepto debemos tener en consideración que el trato debe ser igual para todos en el entendido que cada persona es diferente, más aún, cuando nos referimos a estudiantes extranjeros (ECHEITA; SANDOVAL, 2002).

Ninguno de los tres establecimientos consultados cuenta con prácticas de gestión inclusiva que sean propias de la escuela o que se encuentren sistematizadas. Lo que hace la escuela X, permitir el ingreso a cualquier estudiante independiente de la nacionalidad, corresponde al cumplimiento de la ley y al derecho que tiene cualquier niño en edad escolar a recibir educación, por lo que se podría decir abiertamente que no cuentan con ninguna práctica, a nivel de gestión, que permita la inclusión de estudiantes extranjeros.

El acompañamiento que realiza el establecimiento $Z$ es para todo estudiante nuevo, por lo que no es un beneficio exclusivo del alumno extranjero, lo que indica que tampoco cuentan con prácticas de gestión inclusivas para el estudiantado inmigrante.

Práxis Educativa, Ponta Grossa, v. 15, e2015092, p. 1-24, 2020 
En cuanto al establecimiento Y, según lo mencionado por su director, depende de la voluntad de los docentes y del tiempo que tengan para poder hacer lo que tienen pensado. Por lo que, al igual que los establecimientos anteriores, no cuentan con prácticas de gestión inclusiva.

Las prácticas realizadas por los docentes, como se ha mencionado anteriormente, responden, en primera instancia a la voluntad y al tiempo. Al no existir políticas internas que direccionen el accionar docente frente a estudiantes inmigrantes, los tres equipos directivos manifiestan no poder exigir a los profesores que realicen prácticas inclusivas dentro de la sala de clases.

En el establecimiento $Z$ no hay nada formal que inste a los docentes a realizar alguna práctica en particular con los estudiantes extranjeros, esto principalmente, porque "lo que se hace para uno, se hace para todos" En este establecimiento, son todos los estudiantes tratados como igual. Eso incluye "a la alumna proveniente de India que, no conocía nada de español cuando llegó a vivir a Talca e ingresó al colegio".

Por su parte, en el establecimiento $\mathrm{X}$ hay algunos profesores que traducen los textos o guías a los niños y niñas para que puedan comprenderlas e incluso han traducido libros de lectura complementaria. Si analizamos esto en referencia al tiempo, podemos mencionar que lo realizado por la profesora de lenguaje de la escuela es un gran esfuerzo por favorecer la inclusión de los estudiantes inmigrantes no hispanoparlantes, sin embargo, este esfuerzo no es valorado por su equipo directivo.

El establecimiento $\mathrm{Y}$, cuenta con dos profesores en particular que decidieron realizar modificaciones al currículo para poder hacer más efectivas sus clases. En el caso del profesor de historia, es una decisión personal que no corresponde a un trabajo del departamento de historia. Lo mismo pasa con el profesor de educación física, quien, por opción, decidió aprender los bailes típicos y averiguar las fechas en que los países de los estudiantes extranjeros celebran su independencia e incluir esto en su programación. Con esto, surge una vez más la interrogante ¿quién supervisa que estas adecuaciones estén bien realizadas?

Un factor fundamental en el aprendizaje de los estudiantes es la familia. Es por esto, que una de las preguntas apunta a la vinculación entre las familias inmigrantes y la escuela.

En los tres establecimientos las familias extranjeras se han incluido "igual que los chilenos". Esto apunta específicamente a que participan activamente de "reuniones de microcentro, actividades para padres, como el día del apoderado o baile entretenido".

Los padres y apoderados extranjeros, al igual que sus hijos, se han auto-incluido en los procesos y prácticas que favorezcan su inclusión en el sistema educativo chileno: "Se esfuerzan por participar de las distintas actividades que se realizan en las escuelas y poder ser parte de la comunidad educativa". Sin embargo y en oposición a este deseo de las familias extranjeras por ser parte de la cultura escuela, ninguno de los entrevistados asegura contar con prácticas que favorezcan la vinculación específica de padres inmigrantes a las actividades cotidianas de la escuela.

A modo de reflexión y para finalizar la entrevista, los directivos responden a la pregunta si consideran que algo falta con relación a las políticas educativas de estudiantes extranjeros y de ser así, qué incluirían. Los entrevistados creen que sí hacen falta políticas que permitan incluir estudiantes inmigrantes de manera más adecuada. 
Jorge Alarcón-Leiva, Catalina Gotelli-Alvial e Myriam Díaz-Yáñez

Por otra parte, dicen sentirse ignorantes respecto al expansivo proceso migratorio que vive nuestro país y particularmente la Provincia de Talca, donde en los últimos años las calles se han teñido de diversidad cultural. Reclaman lineamientos claros que vengan desde el Ministerio de Educación y que los orienten a poder realizar el proceso inclusivo de una mejor manera. Los tres coinciden en que se ha hecho muy poco para incluir a los estudiantes inmigrantes y que, si bien se les permite el ingreso y la permanencia en los establecimientos educacionales chilenos, eso no es suficiente.

\section{Conclusiones}

Para comenzar, es necesario hacer hincapié que en repetidas ocasiones los directivos señalan que atienden a los estudiantes "como iguales", sin considerar sus diferencias individuales, lo que indica que la gestión que desarrollan los establecimientos a pesar de ser declarada como inclusiva tiende a asimilar. Esto, porque si bien en los establecimientos reciben estudiantes de distintas culturas, una de sus características es la tendencia a la homogenización que impregna su praxis educativa: "El interculturalismo no acepta la jerarquización cultural ni el etnocentrismo al entender que todas las culturas son igualmente respetables" (SANTOS GUERRA, 2009, p. 183). Este punto es especialmente importante, puesto que nótese que se trata de considerar a las culturas como "igualmente respetables" lo que quiere decir justamente lo contrario a "todos por igual"; más bien, "igualmente respetables en su diferencia” (MICHAEL, 1997a).

En general el estudio permitió, a través de la recolección de información, evidenciar que los establecimientos educacionales han ido aumentando de manera sostenida la matrícula de estudiantes inmigrantes extranjeros. Sin embargo, a pesar del incremento los directivos señalan no contar con normativa interna que permita brindar tratamiento diferenciado a estudiantes que así lo requieran, tampoco prácticas sistematizadas que permitan una adecuada escolarización, ni procesos que favorezcan la participación y aprendizaje del alumnado inmigrante extranjero. La inexistencia de dicha normativa propia no se compadece con la existencia de normas nacionales que hablitarían a los establecimientos escolares a elaborar sus propios reglamentos.

En lo que sigue, se caracterizan los principales desafíos de gestión identificados en el transcurso del trabajo, organizados en cuatro tipos: normativos, pedagógicos, administrativos y financieros.

De acuerdo con lo que reportan las entrevistas, la información que reciben los directivos escolares es acotada y solo proviene del Ministerio de Educación. Al ser limitada, y con ausencia de experiencias migratorias integradoras exitosas, los equipos directivos responden con las mismas prácticas a la nueva situación. Podría sostenerse que la ausencia de normativa adecuadamente procesada por parte de las escuelas, genera que su gestión tienda a ser homogeneizadora $\mathrm{y}$ asimilacionista (MICHAEL, 1997a).

Por otro lado, y de acuerdo con lo analizado en la dimensión de políticas del apartado anterior se puede concluir que, desde el punto de vista de la gestión los equipos directivos entienden que la ley es estrictamente prohibitiva, coartando su accionar e induciendo a no hacer más de lo que está explícitamente prescrito, puesto que asumen que así evitan la ocurrencia de situaciones negativas.

Actualmente, ninguno de los tres establecimientos cuenta con normativas internas que favorezcan la integración de los estudiantes inmigrantes extranjeros, lo que es en sí mismo un acto

discriminatorio. Cabe preguntar, ¿cómo es posible considerarse una escuela "inclusiva", si cuando hay

Práxis Educativa, Ponta Grossa, v. 15, e2015092, p. 1-24, 2020

Disponível em: <https://www.revistas2.uepg.br/index.php/praxiseducativa $>$ 
estudiantes que provienen de otros países dejan de ser quienes son para transformarse en lo que ellos llaman "un chileno más"? ¿No es acaso esta situación un acto de discriminación, por lo que el artículo $1^{\circ}$ de la ley de inclusión no estaría cumpliéndose? (CHILE, 2015b) ¿ O es que la ley es solo para estudiantes chilenos y no corre para quienes provienen de otro país?

Inherentemente esto se relaciona con la norma. Principalmente porque los equipos directivos comentan que, al no existir una normativa a nivel país que respalde sus decisiones como directores y/o líderes educativos, no pueden exigir al cuerpo docente que realice modificaciones al currículo o al proceso evaluativo. Sin embargo, y a pesar que la ley de inclusión no sea explícita en cuanto a estudiantes extranjeros se refiere, los documentos de orientaciones técnicas (CHILE, 2017b) para la integración de dichos estudiantes, están fundamentados en la Ley de inclusión $\mathrm{N}^{\circ} 20.845$ que faculta a los equipos de gestión de las escuelas a proponer normativas propias que concurran al propósito de la escolarización y la inclusión.

Por otra parte, ninguno de los establecimientos cuenta con normativa que facilite la integración pedagógica de los estudiantes inmigrantes extranjeros. Sus actuales reglamentos internos de evaluación no contemplan cómo serán evaluados los estudiantes que, por ejemplo, no hablen castellano. Tampoco hay reglamentación sobre las adecuaciones curriculares que se podrían llevar a cabo cuando las escuelas matriculen estudiantes inmigrantes extranjeros. Lo que han hecho ha sido, según palabras de los directivos, "por la voluntad" o "proactividad" de algunos docentes.

El principal desafío pedagógico al que se enfrentan los establecimientos es realizar modificaciones a nivel curricular que permitan llegar a lo que BANKS (1989; 2006) llama "enfoque de la transformación", para posteriormente alcanzar el "enfoque de toma de decisiones y acción social". Es decir, en la medida en que los establecimientos consideren que no están facultados para "hacer nada más" de lo que la normativa prescribe explícitamente, no habrá posibilidades de visualizar siquiera la necesidad de efectuar adecuaciones curriculares que atiendan a las particularidades de los estudiantes.

Por lo anteriormente expuesto, podemos concluir que existe una dicotomía entre lo que dicen y lo que realmente hacen los equipos directivos en sus establecimientos, dado que durante la entrevista reportan que ellos creen que el trato diferenciado a los estudiantes inmigrantes extranjeros provocará éxito escolar; sin embargo, cuando se pregunta sobre las adecuaciones curriculares, evaluativas o las prácticas pedagógicas, indican que no existe nada sistemático y justifican esta situación aludiendo a la ausencia de normativas en el país, situación que no es el caso.

En cuanto a lo administrativo los establecimientos enfrentan una importante complicación. Cuando reciben estudiantes inmigrantes extranjeros en el transcurso del año ingresan al curso que sigue al último aprobado. Es decir, si el último curso aprobado fue cuarto de enseñanza básica el estudiante debería inscribirse en quinto año. Pero dado que eventualmente no ha cursado el año completo, se producirá un efecto de desfase que redundará en causal de pérdida de aprendizaje.

Esto genera una gran complicación porque, además de no contar con normativa que permita adecuaciones curriculares o evaluativas, la administración no solo no favorece, sino que eventualmente dificulta la inclusión del estudiante en términos del aprendizaje y participación requeridos, por lo que el proceso de su inclusión se verá afectado negativamente.

Por otra parte, ninguno de los tres establecimientos cuenta con estadísticas de aprobación/reprobación de los estudiantes inmigrantes extranjeros lo que impide establecer 
Jorge Alarcón-Leiva, Catalina Gotelli-Alvial e Myriam Díaz-Yáñez

comparaciones entre cómo llegaron y cuánto han avanzado en la escuela. Si se dispusiera de tales antecedentes, se podría efectuar adecuaciones curriculares que favorecieran su progresión en la trayectoria escolar.

Otro punto que menciona la UTP del establecimiento X es respecto de la prueba que deben rendir los estudiantes para ubicarlos en algún curso, una vez que se han matriculado. Chile es parte de un convenio de convalidación de estudios con varios países de la región. Haití no ha sido uno de ellos, sin embargo, y dada la sostenida llegada de personas de esa nacionalidad al país, es que en junio de 2017 comienza a regir el "Convenio Chile-Haití" que busca la convalidación de estudios de básica o primaria, media o secundaria (CHILE, 2017a).

Sin embargo, además de la convalidación —como se ha indicado-, el instrumento de evaluación no existe de modo estándar, en consecuencia, cada establecimiento termina procediendo conforme al mejor juicio de sus docentes. En todos los casos, sin criterios técnicos compartidos. Es importante mencionar que, para aplicar el instrumento el establecimiento puede hacerlo hasta el último trimestre del año escolar, es decir, el estudiante inmigrante extranjero eventualmente debe esperar un año antes de ser evaluado e integrado al curso que le corresponde.

Los últimos desafíos pesquisados se relacionan con el ámbito financiero. Según palabras de la UTP del establecimiento X, "conviene" integrar matrícula al establecimiento, esto es, una parte del requerimiento anual del establecimiento implica aumentar la matrícula de estudiantes. Por lo que, desde este punto de vista, los estudiantes inmigrantes extranjeros se suman al actual sistema escolar chileno, en el que los establecimientos dependen financieramente del número de estudiantes que matriculen anualmente. Sin embargo y a pesar que recibir estudiantes inmigrantes extranjeros significa un aporte monetario, por concepto de subvención o mensualidad, este aporte financiero no es proporcional al especial apoyo requerido por los estudiantes inmigrantes extranjeros.

Para que los profesores pudieran acceder a realizar adecuaciones curriculares que integren a los inmigrantes, es necesario que dispongan de tiempo. Este tiempo, se transforma en horas de contrato, lo que a su vez implica un costo financiero. Como es sabido, la subvención escolar no es significativa si se requiere aumentar o redistribuir la carga horaria docente. En el caso de un estudiante que tenga seis asignaturas diferentes (sabemos que son más, pero es solo a modo de ejemplo) se debería aumentar la carga horaria a esa misma cantidad de docentes, sin embargo, la subvención percibida es mucho más baja que lo que costaría pagar esas horas a los docentes, por lo que es muy poco probable que se pueda aumentar la carga horaria a los profesores que trabajan con estudiantes inmigrantes.

Sin duda los desafíos anteriormente planteados se relacionan entre sí. No es posible realizar cambios estructurales y substanciales dentro de la escuela, si los equipos directivos no manejan la normativa respecto de estudiantes inmigrantes $y$, por otra parte, si los directivos no cuentan con el apoyo de sus sostenedores se hará complejo realizar adecuaciones que, por ejemplo, intervengan la distribución horaria de los profesores.

Tres breves puntualizaciones finales. Parte relevante de la evidencia aportada por el estudio confirma, por una parte, la importancia de la inmigración extranjera para el sistema educativo. Por otra parte, la evidencia también pone de relieve la prevalencia de formas de distribución de la matrícula, que favorecen al sector particular subvencionado y particular privado, puesto que, por contraste con estos dos el sector de la educación municipal (pública) tiende a concentrar estudiantes con menor capital cultural y social. Enseguida, el comparativo menor desarrollo evidenciado en Chile por la carrera

Práxis Educativa, Ponta Grossa, v. 15, e2015092, p. 1-24, 2020 Disponível em: <https://www.revistas2.uepg.br/index.php/praxiseducativa $>$ 
profesional como directivo escolar, se presenta como una desventaja para lograr una atención educativa plenamente inclusiva de estudiantes inmigrantes extranjeros en el supuesto que la profesionalización de los directivos escolares, implique una mejor respuesta a esta nueva demanda para el sistema escolar en su conjunto.

\section{Referencias}

ARAVENA CASTILLO, F. et al. Liderazgo escolar: una mirada a los criterios de éxito pedagógico de los jefes de Unidad Técnica Pedagógica (UTP) en Chile. Calidad en la Educación, n. 51, p. 252-280, 2019. DOI: https://doi.org/10.31619/caledu.n51.647

BANKS, J. A. Approaches to multicultural curriculum reform. Trotter Review, v. 3, n. 3, p. 16-19, 1989.

BANKS, J. A. Race, culture, and education. The selected works of James A. Banks. USA \& Canada: Routledge, 2006.

BERRY, J. W. et al. Immigrant youth: acculturation, identity, and adaptation. Applied Psychology: an international Review, v. 55, n. 3, p. 303-332, 2006.

BOLÍVAR BOTÍA, A. Liderazgo, mejora y centros educativos. In: MEDINA, A. (org.). E1 liderazgo en educación. Madrid: UNED, 1997. p. 25-46. Recuperado de <http://centroderecursos.educarchile.cl/bitstream/handle/20.500.12246/1126/201103071614300. UNED\%20Liderazgo_Mejora_y_Centros_Educativos.pdf?sequence=1>. Acceso: 8 maio 2020.

CAMPOS VERGARA, F.; VALDÉS MORALES, R.; ASCORRA COSTA. P. ¿Líder pedagógico o gerente de escuela? Evolución del rol del director de escuela en Chile. Calidad en la Educación, v. 51, p. 53-84, 2019. DOI: https://doi.org/10.31619/caledu.n51.685

CASTLES, S., DE HAAS, H. G.; MILLER.; MILLER, M. J. The age of migration. international Population Movements in the Modern World. 5. ed. UK: Palgrave Macmillan, 2014.

CHILE. Ministerio de Educación. Ley n. 20.370. Ley General de Educación. Santiago, Chile, 2009. Recuperado de <https://www.leychile.cl/N?i=1006043\&f=2009-09-12\&p=>. Acceso: 8 maio 2020.

CHILE. Ministerio de Educación. Marco para la Buena Dirección y Liderazgo Escolar, 2015a. Recuperado de < http://liderazgoescolar.mineduc.cl/wpcontent/uploads/sites/55/2016/04/MBDLE_2015.pdf>. Acceso: 8 maio 2020.

CHILE. Ministerio de Educación. Ley n. 20.845, 2015b. Inclusión Escolar que Regula la Admisión de los y las Estudiantes, Elimina el Financiamiento Compartido y Prohíbe el Lucro en Establecimientos Educacionales que Reciben Aportes del Estado, Santiago, Chile. Recuperado de <https://www.leychile.cl/Navegar?idNorma=1078172 >. Acceso: 8 maio 2020. 
Jorge Alarcón-Leiva, Catalina Gotelli-Alvial e Myriam Díaz-Yáñez

CHILE. Ministerio de Educación. Plan de apoyo a la inclusión. 2016. Recuperado de $<$ http://escolar.mineduc.cl/inclusion-convivencia-e-interculturalidad/inclusion>. Acceso: 8 maio 2020.

CHILE. Ministerio de Relaciones Exteriores. Decreto n. 114. Promulga el Acuerdo Complementario al Convenio Básico de Cooperación Científica y Técnica entre el Gobierno de la República de Chile y el Gobierno de la República de Haití para la Equiparación o Equivalencia y Reconocimiento de Estudios de los Niveles de Enseñanza Básica o Primaria y Media o Secundaria, 2017a. Recuperado de <https://migrantes.mineduc.cl/wp-content/uploads/sites/88/2018/06/Convenio-Chile-Haitj-

Diario-Oficial.pdf $>$. Acceso: 8 maio 2020.

CHILE. Ministerio de Educación. División de Educación General. Coordinación Nacional de Inclusión y Diversidad. Orientaciones técnicas para la inclusión educativa de estudiantes extranjeros, 2017b. Recuperado de <https://www.ayudamineduc.cl/sites/default/files/orientaciones-estudiantes-extranjeros-21-1217.pdf>. Acceso: 8 maio 2020.

CHILE. Ministerio de Educación. Centro de Estudios. Mapa del estudiantado extranjero en el sistema escolar chileno (2015-2017). Documento de trabajo n. 12. Santiago, Chile, 2018a. Recuperado de $<$ https://www.mineduc.cl/wpcontent/uploads/sites/19/2018/05/MAPA_ESTUDIANTES_EXTRANJEROS_SISTEMA_ESC OLAR_CHILENO_2015_2017.pdf>. Acceso: 8 maio 2020.

CHILE. Ministerio d Educación. Política Nacional de Estudiantes Extranjeros 2018-2022, 2018b. Recuperado de <https://migrantes.mineduc.cl/wp-content/uploads/sites/88/2018/06/POLITICANACIONAL-EE-Final-1-1.pdf>. Acceso: 8 maio 2020.

CIERANI CERNADAS, P.; GARCÍA, L.; GÓMEZ SALAS, A. Niñez y adolescencia en el contexto de la migración: principios, avances y desafíos en la protección de sus derechos en América Latina y el Caribe. REMHU: Revista Interdisciplinar da Mobilidade Humana., Brasília, v. 22, n. 42, p. 9-28, jan./jun. 2014. DOI: https://doi.org/10.1590/S1980-85852014000100002

CONTRERAS, D.; CORTÉS, S.; FABIO, C. Niños, niñas y adolescentes migrantes y su derecho a la educación en Chile. In: ACNUR. Alto Comisionado de las Naciones Unidas para los Refugiados. Organización Internacional para las Migraciones. Los derechos de los niños, niñas y adolescentes migrantes, refugiados y víctimas de trata internacional en Chile. Avances y desafíos, 2010. p. 217-242. Recuperado de <https://www.unicef.cl/web/wpcontent/uploads/doc_wp/NINOS\%20MIGRANTES\%20baja.pdf>. Acceso: 8 maio 2020.

DÍAZ-BRAVO, L. et al. La entrevista, recurso flexible y dinámico. Investigación en educación médica, v. 2, n. 7, p. 162-167, jul./set. 2013.

ECHEITA SARRIONANDIA, G.; SANDOVAL MENA, M. Educación inclusiva o educación sin exclusiones. Revista de Educación, n. 327, p. 31-48, 2002. 
FRANCO GARCIA, M. Sistemas educativos y migración. Una mirada a la educación en Estados Unidos y México. RMIE, v. 22, n. 74, p. 705-728, set. 2017.

GAlaZ VALDERrAmA, C.; POBLETE MELIS, R.; FRÍAS ORTEGA, C. Políticas Públicas e Inmigración ¿Posibilidades de Inclusión efectiva en Chile? Santiago de Chile: Editorial Universitaria. 2017

INE, INSTITUTO NACIONAL DE ESTADÍSTICAS, CHILE. Entrega final Censo 2017.

JIMÉNEZ, F. V. Modelos de gestión de la diversidad cultural para la escolarización de alumnado inmigrante en las escuelas chilenas: desafíos para la interculturalidad actual. Estudios Pedagógicos, v. 40, n. 2, p. 409-426, 2014. DOI: http://dx.doi.org/10.4067/S0718-07052014000300024

JIMÉNEZ GAMEZ, R. Inmigración, interculturalidad y currículum. La educación en una sociedad multicultural. Morón (Sevilla): Publicaciones del M.C.E.P, 2004.

JIMÉNEZ VARGAS, F.; AGUILERA VALDIVIA, M.; VALDÉS MORALES, R.; HERNÁNDEZ YÁÑEZ, M. Migración y escuela: análisis documental en torno a la incorporación de inmigrantes al sistema educativo chileno. Psicoperspectivas, v. 16, n. 1, p. 105-116, 2017. DOI: https://doi.org/10.5027/psicoperspectivas-vol16-issue1-fulltext-940

JORDÁN SIERRA, J. La escuela multicultural: Un reto para el profesorado. Barcelona. Paidós, 1994.

LEITHWOOD, K.; DAY, C.; SAMMONS, P.; HARRIS, A.; HOPKINS, D. Successful school leadership: what it is and how it influences pupil learning. London, UK: Department for Education and Skills, 2006.

LEIVA-GUERRERO, M.; VÁSQUEZ, C. Liderazgo pedagógico: de la supervisión al acompañamiento docente. Calidad en la Educación, v. 51, p. 225-251, 2019. DOI: https://doi.org/10.31619/caledu.n51.635

MICHAEL, S. O. Models of Multiculturalism: implications for the twenty-first century leaders. European Journal of Intercultural Studies, v. 8, n. 3, p. 231-245, 1997. DOI: http://dx.doi.org/10.1080/0952391970080302

OLIVEIRA, D. A. O imigrante na política educacional brasileira: um sujeito ausente. Práxis Educativa, Ponta Grossa, v. 15, e2013655, p. 1-15, 2020. DOI: https://doi.org/10.5212/PraxEduc.v.15.13655.004

ORGANIZACIÓN DE LAS NACIONES UNIDAS (ONU). Declaración Universal de Derechos Humanos. 1948. Recuperado de: <https://www.un.org/es/universal-declaration-human-rights/>. Acceso: 18 abril 2020. 
Jorge Alarcón-Leiva, Catalina Gotelli-Alvial e Myriam Díaz-Yáñez

ORGANIZACIÓN INTERNACIONAL PARA LAS MIGRACIONES. Dinámicas migratorias en fronteras de países de América del Sur. Cuaderno n. 10, 2018. Recuperado de $<$ https://robuenosaires.iom.int/sites/default/files/publicaciones/Cuaderno_10-

Dinamicas_Migratorias_en_Fronteras_de_paises_de_America_del_Sur.pdf $>$. Acceso: 8 maio 2020.

PAVEZ-SOTO, I. La niñez en las migraciones globales: perspectivas teóricas para analizar su participación. Tla-Melaua, Revista de Ciencias Sociales, México, v. 10, n. 41, p. 96-113, out. 2016/mar. 2017,

POBLETE MELIS, R. Niños y niñas migrantes: trayectorias de inclusión educativa en escuelas de la región metropolitana informe final de investigación (Investigación realizada para la Superintendencia de Educación de Chile). 2016. Recuperado de <https://www.supereduc.cl/wpcontent/uploads/2017/01/Informe-Final-de-Investigacion-Migrantes.pdf>. Acceso: 8 maio 2020.

POBLETE MELIS, R.; GALAZ VALDERRAMA, C. La identidad en la encrucijada: migración peruana y educación en el Chile de hoy. EMIGRA Working Papers, 3 ed. 2007. Recuperado de <https://ddd.uab.cat/pub/emigrawp/emigrawp_a2007n3/emigrawp_a2007n3p1.pdf>. Acceso: 8 maio 2020 .

POZZO, M.; SOLOVIEV, K. Culturas y lenguas: la impronta cultural en la interpretación lingüística. Tiempo de Educar, v. 12, n. 24, jul./dez. 2011.

ROJAS-PEDEMONTE, N.; DITTBORN, C. S. La Migración en Chile: breve reporte y caracterización. In: GARCIA, N.; ESTRADA, C. Informe do Observatorio Iberoamericano sobre Movilidad Humana, Migraciones y Desarrollo (OBIMID), jul./ago. 2016.

RUIZ-TAGLE, C. Selección de directivos escolares en base a procesos competitivos: evidencia de una política para Chile. Calidad en la Educación, v. 51, p. 85-130, 2019. DOI: https://doi.org/10.31619/caledu.n51.646

SANTOS GUERRA, M. Á. El valor de la convivencia y el reto de la interculturalidad. Eikasia. Revista de Filosofía, v. 5, n. 28 p. 175-200, set. 2009.

SUÁREZ-CABRERA, D. L. Nuevos migrantes, viejos racismos: Los mapas parlantes y la niñez migrante en Chile. Revista Latinoamericana de Ciencias Sociales, Niñez y Juventud, v. 13, n. 2, p. 627-643. 2015.

UNESCO. Directrices UNESCO sobre la educación intercultural. UNESCO, París, 2006. Recuperado de <https://unesdoc.unesco.org/ark:/48223/pf0000147878_spa>. Acceso: 8 maio 2020.

VARGAS, ARRIAGADA. J. Extranjeros en la escuela: una oportunidad para recuperar el sentido de la educación (Tesis de Magister). Inédita. Universidad de Talca, Talca, Chile, 2018. 
VÁZQUEZ TOLEDO, S.; BERNAL AGUDO, J.; LIESA ORÚS, M. La Conceptualización del Liderazgo: Una Aproximación desde la Práctica Educativa. Revista Iberoamericana sobre Calidad, Eficacia y Cambio en Educación, v. 12, n. 5. 2016.

Recibido: 04/04/2020

Versión corregida recibida: 06/05/2020

Aceptado: 08/05/2020

Publicado online: $13 / 05 / 2020$ 